\title{
Correction to: Effects of roasting conditions on physicochemical properties and antioxidant activities in Ginkgo biloba seeds
}

\author{
Heung-Bin $\mathrm{Lim}^{2} \cdot$ Dong-Ho Kim ${ }^{1}$
}

Published online: 25 September 2018

(C) The Korean Society of Food Science and Technology and Springer Science+Business Media B.V., part of Springer Nature 2018

Correction to: Food Sci Biotechnol (2018) 27(4):1057-1066

https://doi.org/10.1007/s10068-018-0348-7

Unfortunately, first author Heung-Bin Lim's affiliation was missed to include in the original version of this article. The affiliation of Heung-Bin Lim should be:

Industrial Crop Science and Technology, Chungbuk National University, Cheongju, Chungbuk, 28644, Korea

The original article can be found online at https:// doi.org/10.1007/s10068-018-0348-7.

\footnotetext{
Dong-Ho Kim

dh3034@hanmail.net; dongho3034@gmail.com

1 Department of Food Service and Culinary Arts, Seowon University, Cheongju, Chungbuk 28674, Korea

2 Industrial Crop Science and Technology, Chungbuk National University, Cheongju, Chungbuk 28644, Korea
} 